London

melanienewman999@gmail.com Cite this as: BMJ 2021;373:n1559 http://dx.doi.org/10.1136/bmj.n1559 Published: 24 June 2021
COVID-19

\section{Chronic fatigue syndrome and long covid: moving beyond the controversy}

\section{Many patients with "long" covid are experiencing extreme fatigue, a situation that has re-polarised approaches to treatment and rehabilitation. Melanie Newman reports}

\section{Melanie Newman freelance journalist}

"I submitted the first positive trial of cognitive behavioural therapy [CBT] as a treatment for chronic fatigue in the '9os," recalls Michael Sharpe, a professor of psychological medicine who was then a lecturer at Oxford University. "Next thing, my head of department got an unsigned letter, sent to The BMJ, saying that the research study was made up."

It was the start of a lengthy campaign to prevent and undermine his research by some advocates of chronic fatigue syndrome/myalgic encephalomyelitis (CFS/ME) who object to suggestions that their illness has a psychological element.

After a period of "a lot of awfulness" Sharpe moved to Edinburgh University, where he initially decided to abandon the field but was drawn back by the Pace trial. ${ }^{1}$ Pace examined the effectiveness of CBT and graded exercise therapy (GET), in which the patient does progressively more exercise over time, combined with medical care. It was always going to be controversial.

"The Medical Research Council was being lobbied, people were trying to stop participants joining the trial-we had so much flak," he says. Published in 2011 in the Lancet, the Pace trial found that both CBT and GET led to greater improvements in some participants than medical care alone. Since then the trial has been a lightning rod for ME/CFS advocates' anger, drawing ceaseless attacks on the conduct of the research, the researchers, and the results.

A decade after publication it seems unlikely that a consensus will ever be reached. The National Institute for Health and Care Excellence has since reviewed its guidance on ME/CFS, and the draft guidance ${ }^{2}$ expresses concerns about inappropriate use of exercise and CBT, stating that the evidence is mixed or unclear.

Tensions have now resurfaced with the advent of the pandemic and "long" covid or post-covid symptoms. As many as 376 ooo people in the UK report symptoms more than 12 months after the first onset of covid- $19,{ }^{3}$ often experiencing extreme fatigue along with a wide range of other symptoms.

Clinicians report a complex picture. Patients with long covid are a diverse group, and it's hard to know what treatment path to put them on. Finding the right balance between gentle activity to avoid deconditioning and not triggering post-exercise malaise is important in each patient. But the advice given, the research conducted, and how it is communicated have become highly sensitive issues.

The BMJ has spoken to clinicians and academics who have been challenged over their views on treatment of long covid, or their research intentions, where "exercise" has become a toxic term for some. Clinicians working with long covid patients have also told The BMJ that, despite the challenges, long covid provides an opportunity to progress the understanding of postviral syndromes and to acknowledge that they are a very real condition.

\section{Challenged for speaking out}

The pandemic has seen Sharpe back in Oxford, helping to set up a multidisciplinary long covid clinic involving medical specialists, physiotherapists, occupational health practitioners, and psychologists. Clinics of this sort, with a similar range of clinical expertise, have been set up around the UK.

The insurance company Swiss $\mathrm{Re}$-with which Sharpe makes clear that he has no financial link-asked him to do a presentation on early observations at the clinic. The slides from his talk showed that long covid encompasses a range of conditions, with symptoms influenced by biological, psychological, and social factors, including media coverage, and that it has some similarities with CFS/ME.

“We need to balance 'keeping an open mind' with a pragmatic approach to management," the slides advised. "Patients need to feel listened to and believed-physicians must manage uncertainty." Referencing the Pace trial, they added, "At present the best treatment is psychologically informed rehabilitation." ${ }^{45}$ However, while most patients will improve, "there is likely to be some long term disability.” presentation-and, as an example of the role of media coverage, a quote from the Guardian journalist George Monbiot-set the hares running. In April Monbiot wrote a follow-up piece that began, "A super-spreader has been identified ... it's me." ${ }^{6}$ He went on to rehash criticisms of the Pace trial without mentioning that they had been investigated by the Health Research Authority. ${ }^{7}$

Many readers castigated Sharpe for suggesting that the disease was "all in the mind" or created by the media, while others defended him on the same basis. One patient said in the comments section, “As
Sharpe's inclusion of the Pace trial in his 
someone who is lying in bed, yet again unable to work and in agony due to long covid, I find this professor's comments so hurtful. This is a serious physical illness, not some social hysteria."

Other doctors who have entered the debate have quickly found themselves under fire. Trish Greenhalgh, professor of primary care at Oxford University, commented on exercise and the Pace trial at a public webinar on long covid, hosted in January by the Canadian Institute of Musculoskeletal Health and Arthritis. Her remarks are not publicly available, but Greenhalgh says that she summarised the controversy and that her position was misrepresented as pro-GET; however, other attendees say that she went beyond this and criticised CFS/ME activists.

A short while later she received an email from the organiser of another online conference at which she was due to speak about long covid. An ME advocate had contacted the organiser to complain about Greenhalgh's participation on the basis of her "maligning characterisation" of CFS/ME patients and her "promotion of discredited and harmful research.” The message concluded, "Dr Greenhalgh is a patient safety threat to all Canadians living with ME and long covid," and it asked for her removal from the speaker line-up. The organiser told Greenhalgh that it knew people in the UK with similar experiences who had subsequently refused to have anything more to do with CFS/ME.

\section{In the spotlight}

But few opinions on long covid have proved as contentious as those of Paul Garner, professor at the Liverpool School of Tropical Medicine. A few months after contracting the virus in March 2020, and after a period of fatigue and other symptoms of long covid, Garner, who had previously been extremely fit, felt a little better, went for a long cycle ride, and took part in a high impact exercise class. He immediately relapsed.

Experiencing fatigue and what he describes as "brain fog," he found the medical literature and guidance "pretty hopeless" on convalescence, while the CFS/ME literature was "very helpful." It explained that he was experiencing "post-exertional malaise": a hallmark symptom of ME/CFS in which exercise triggers a worsening of symptoms.

Garner took advice to accept the limits imposed by the virus. The ME Association recommends "pacing" 8 : slowly building up activity levels while monitoring one's response to exertion and limiting activities accordingly to prevent post-exertional malaise. It says that vigorous exercise should be avoided until recovery has been complete for some time.

He attempted pacing ${ }^{9}$ but struggled to discover a pattern between his activities and his symptoms that might help him recover. Three months after contracting covid, he says, he was unable to get out of bed for more than a few hours each day. "I kept trying to convince myself I was getting better, but I wasn't, and I became too insecure to do anything," he explains.

Weeks turned into months. A CFS/ME advocate wrote an open letter ${ }^{10}$ to people with long covid telling them to "brace yourself," as "you might not end up being sick for a couple of months or a year or even five years. Think decades. Maybe even the rest of your life." Garner says that he became stressed, locked into a pattern of symptom monitoring to prevent relapses and an unconscious fear of "overdoing it."

He then spoke to a recovered CFS/ME patient, who committed to helping him recover. Core to this was a compelling explanation of what was happening in relation to the brain and body, which, he says, "changed my understanding of the symptoms I was experiencing." The support included a credible explanation of his symptoms, his hope of recovery, and techniques to reduce his symptoms and stress. He went on a short bike ride and then, under physician supervision, increased the lengths of his ride over several weeks-a process that he says was essentially GET. "It stopped me doing too much," he says. "It was very gradual.” He progressed to full health within a few weeks.

Garner believes that the non-specific concept of post-exertional malaise can cause patients to fear activities and overexertion. He also suggests that the malaise after exercise is normal early on but that it then becomes a learnt automatic brain response.

"I think it is really important not to emphasise post-exertional malaise as if it is a disease," he explains. "Early on I got suckered into it as something that might never go away. Part of my recovery has been around changing my thoughts around different body signals. If you see any signal as abnormal you feel insecure or get stressed, the most minor feelings get exaggerated by your brain, and you take to your bed."

Perhaps unsurprisingly, having written in The BMJ that he had "looked down the barrel of the ME/CFS gun and disarmed it,"11 Garner found that the CFS/ME community, which had previously embraced him, turned on him. And, having previously criticised Cochrane's recommendation of exercise therapy, ${ }^{12}$ he added fuel to the flames when he called for more research on GET and claimed that no trials had harmed patients. ${ }^{13}$

His theory was that rest and pacing, as advocated by CFS/ME charities, were initially as vital as convalescence in the first few months but that symptom monitoring may become counterproductive. For such patients, he said, gradually and slowly increasing physical activity would be beneficial. This was interpreted as an order forcing exercise on unwilling patients and was rejected by the CFS/ME community.

Garner says that some advocates actively oppose research on exercise. "They believe the disease lasts for life," he says. "They reject any research that examines psychological approaches to treatment or that evaluates the role of progressive physical activity in recovery in ME/CFS, and I would assume by extension to long covid.”

\section{Not against "exercise"}

The ME Association's website carries a statement from its medical adviser, Charles Shepherd, that "the percentage of people who recover [from severe $\mathrm{ME} / \mathrm{CFS}$ ] and return to full normal health is small and ... 'spontaneous recovery' is almost unheard of."14

Shepherd told The BMJ, "We have never issued anything to say that the prognosis indications for long covid are the same as ME. I fear that some do have a long term condition, but it's also clear that many people are recovering."

ME/CFS advocates say that Garner's experience has acquired disproportionate importance while being essentially a single anecdotal account from a person who never fulfilled the criteria for an ME/CFS diagnosis. Shepherd suggests that Garner has received so much media attention because his account seems to confirm a long held theory about ME: that postviral patients were developing abnormal beliefs and behaviours and becoming deconditioned, which could be fixed with CBT and GET.

The ME Association's view is that there is an as yet poorly understood physiological explanation for ME/CFS and long covid, which may be linked to increased levels of inflammatory cytokines 
after initial infection. ${ }^{15}$ It believes that research should focus on this process rather than on exercise and psychological

therapies-and that any recommendation for exercise should come with a health warning.

"We are not against exercise," Shepherd told The BMJ. "Our view is that graded exercise can be harmful."

In a 2019 survey of more than $2000 \mathrm{ME} / \mathrm{CFS}$ patients commissioned by the charity Forward ME, ${ }^{16}$ most patients reported worse symptoms after GET. In the National Institute for Health and Care Excellence's recent draft guidelines on $\mathrm{ME} / \mathrm{CFS}^{2}$ - which considered other research including a separate survey of patients with severe $\mathrm{ME} / \mathrm{CFS}$, as well as criticism of therapist delivered treatments-a recommendation for GET/CBT has been removed, saying that the evidence is mixed or unclear. Meanwhile, long covid researchers are also learning to live with the increased level of scrutiny and complaints that teams working on CFS/ME have come to expect.

Gordon McGregor, a clinical exercise physiologist, is leading the University of Warwick's Regain trial, ${ }^{17}$ a National Institute for Health Research funded study on whether physical activity with psychological support benefits long covid patients who were admitted to hospital. He told The BMJ that he had engaged with a number of CFS/ME patient and advocacy groups. "We had constructive conversations and made a number of amendments to the trial protocol as a result," he says. "We will be screening participants regularly for PEM [post-exertional malaise].”

However, some individuals, who believe that physical activity should be avoided at all costs, remain deeply unhappy and have emailed McGregor, colleagues, and funders with their views. "The impact has been tangible," he says, "but the research is continuing."

\section{Does exercise make patients worse?}

Ben Marsh was an NHS consultant paediatrician who "ran half marathons to relax" before contracting viral pericarditis in 2017 . He went back to work after six months but later developed more severe symptoms and has not recovered despite "extensive professional input."

For some people with low level postviral fatigue, Marsh explains that rest in the early stages, followed by a gradual increase in activity with or without psychological support, can be appropriate. "However, for some people this approach is detrimental to their health," he adds. "The flaw is that this other side of rehab is rarely understood by practitioners or explained to the patient. There is a need to screen patients with fatigue during rehab for PEM [post-exertional malaise]."

The NHS's Your Covid Recovery website tells patients to gradually build up to 30 minutes' activity five days a week and not to give up if they have setbacks. It does not warn of PEM.

Marsh thinks that it should. He says that physical therapy should be treated like a medicine or surgery. "If you take a drug you have to be told the side effects and what to look out for," he says. Asked whether over-emphasising side effects may risk causing them, he responds, "There may be a small number of people with a psychological vulnerability who somatise, but that does not justify failing to make doctors and patients aware of the risks."

\section{Mixed results}

The $B M$ J has spoken to other doctors and healthcare professionals helping long covid patients and found them to be very aware of these concerns, as well as the risk of PEM and the ME/CFS literature. Away from the fire and fury of social media, they are quietly working out how best to treat each patient without causing harm. Results are-predictably, given the early stage of the research-mixed.

Sally Singh, professor of pulmonary and cardiac rehabilitation at the University of Leicester, says that she was "aware of the rhetoric around exercise making people worse, and it was an absolute priority that we didn't do that, which is why we added in a measure of fatigue when monitoring outcomes."
She studied 30 patients who took part in an individually tailored six week rehabilitation programme of aerobic exercise, strength training, and educational discussions. Of the 30 participants only one patient, a stroke survivor, did not improve either exercise capacity or fatigue, while four reported an increase in fatigue but also in exercise capacity.

Meanwhile, in the community rehabilitation arm of the Oxford long covid clinic, Rachael Rogers, a CFS/ME specialist who works alongside a respiratory medicine consultant, has seen some patients with PEM. She says, "We are not advocating exercise for them-we try to establish a baseline of activity that stops the relapsing pattern, the boom and bust. But it's certainly not all long covid patients who get PEM, and there is another set of patients for whom exercise is appropriate."

The key is careful screening, assessment, and individualised treatments, explains Rogers, as "it's not one size fits all." Difficulties may arise, she says, where services are not funded to screen patients properly.

\section{Diverse groups}

Paul Whitaker, a respiratory consultant who set up the first long covid clinic in Yorkshire, told The BMJ that he had studied CFS and postviral literature and was aware of the ME/CFS views around exercise from the outset. "For my longstanding patients with long covid who fulfil the criteria for CFS, they do seem to get worse with strenuous aerobic exercise," he says. "However, long covid is a very diverse group, and there are many others who do need an exercise based regimen." Defining which groups will benefit from exercise remains a challenge.

Rob Barker-Davies is a squadron leader, postdoctoral researcher, and registrar in rehabilitation, sport, and exercise medicine at the Defence Medical Rehabilitation Centre. He told a BMJ webinar on long covid, "We are not advocating fixed increments in activity or assuming linear resolution of symptoms." ${ }^{18}$ He describes the programme offered at the centre as "symptom titrated physical activity," as opposed to graded exercise therapy.

"We mustn't shirk away from the key training principle of progression," he says. "But... we need to understand the effect of the change we've made before proceeding. Otherwise we risk a stepwise deterioration." His patients, who as military personnel are fitter and younger than average, also need educating on managing their activity to avoid "boom and bust," he says.

Barker-Davies draws a comparison between long covid symptoms and those of "over-training syndrome," where athletes over-exercise and can experience fatigue, depression, tachycardia, insomnia, and irritability. He explains that possible causes of over-training syndrome-such as autonomic dysregulation, increased inflammatory cytokines, and dysregulation of the hypothalamus-are all mechanisms that have also been proposed as explanations for long covid.

Competing interests: None declared.

Provenance and peer review: Commissioned; externally peer reviewed.

White PD, Goldsmith KA, Johnson AL. PhD, et al. Comparison of adaptive pacing therapy, cognitive behaviour therapy, graded exercise therapy, and specialist medical care for chronic fatigue syndrome (PACE): a randomised trial. Lancet2011;377:823-36. https://www.thelancet.com/journals/lancet/article/PIIS0140-6736(11)60096-2/fulltext.

2 National Institute for Health and Care Excellence. Myalgic encephalomyelitis (or encephalopathy)/chronic fatigue syndrome: diagnosis and management. In development [GID-NG10091]; expected publication 18 Aug 2021. https://www.nice.org.uk/guidance/indevelopment/gid-ng10091.

Davis N. 376000 people in UK have had long Covid symptoms for at least a year-ONS. Guardian 2021 Jun 4. https://www.theguardian.com/society/2021/jun/04/1-million-people-in-uk-reportexperiencing-long-covid.

4 Singh SJ, Barradell AC, Greening NJ, etal. British Thoracic Society survey of rehabilitation to support recovery of the post-COVID-19 population. BMJ Open 2020;10:e040213.

doi: 10.1136/bmjopen-2020-040213. https://bmjopen.bmj.com/con-

tent/10/12/e040213. pmid: 33268418

Daynes E, Gerlis C, Chaplin E, Gardiner N, Singh SJ. Early experiences of rehabilitation for individuals post-COVID to improve fatigue, breathlessness exercise capacity and cognition-a cohort study. Chron Respir Dis 2021. doi: 10.1177/14799731211015691. https://jour-

nals.sagepub.com/doi/full/10.1177/14799731211015691.

6 Monbiot G. Apparently just by talking about it, I'm super-spreading long covid. Guardian 2021 Apr 14. https://www.theguardian.com/commentisfree/2021/apr/14/super-spreading-long-covidprofessor-press-coverage. 
7 Health Research Authority. Letter to Norman Lamb: Re: The PACE trial and the Committee's inquiry on Research Integrity. 29 Jan 2019. https://www.parliament.uk/globalassets/documents/commons-committees/science-technology/Correspondence/190129-Sir-Jonathan-Montgomery-Health-Research-Authority-to-Chair-re-PACE-trial.pdf.

8 Shepherd C. Energy management in ME/CFS. ME Association. Feb 2020. https://meassociation.org.uk/wp-content/uploads/Energy-Management-Pacing-1.pdf.

9 Garner P. Paul Garner: Covid-19 at 14 weeks - phantom speed cameras, unknown limits, and harsh penalties. BMJ Opinion2020 Jun 23. https://blogs.bmj.com/bmi/2020/06/23/paul-garnercovid-19-at-14-weeks-phantom-speed-cameras-unknown-limits-and-harsh-penalties/.

10 Johnson C. An open letter to the covid-19 long hauler community from a person with ME/CFS. Health Rising 2020 Jul 24. https://www.healthrising.org/blog/2020/07/24/open-letter-covid-19long-hauler-me-cfs/.

11 Garner P. Paul Garner: on his recovery from long covid. BMJ Opinion 2021 Jan 25. https://blogs.bmj.com/bmi/2021/01/25/paul-garner-on-his-recovery-from-long-covid/.

12 Garner P. Paul Garner on long haul covid-19-Don't try to dominate this virus, accommodate it. BMJ Opinion 2020 Sep 4. https://blogs.bmj.com/bmi/2020/09/04/paul-garner-on-long-haulcovid-19-dont-try-and-dominate-this-virus-accommodate-it/.

13 Miller A, Garner P, White P. Letter: Long Covid and graded exercise therapy. Guardian $2021 \mathrm{Mar}$ 11. https://www.theguardian.com/society/2021/mar/11/long-covid-and-graded-exercise-therapy.

14 ME Association. What is the prognosis for someone severely affected by ME? 28 Jul 2017. https://meassociation.org.uk/2017/07/what-is-the-prognosis-for-someone-severely-affected-bym-e-28-july-2017/.

15 Shepherd C. Post covid-19 fatigue, post/long covid-19 syndromes and post-covid ME/CFS. Nov 2020. https://meassociation.org.uk/wp-content/uploads/MEA-Covid-19-MECFS-Post-Covid-Fatigue-Syndromes-and-Management-November-2020.pdf.

16 Forward-ME. Results of the Forward-ME survey for CBT and GET. 2019. https://www. meresearch.org.uk/wp-content/uploads/2019/04/Amended-Final-Consolidated-Report.pdf.

17 Warwick Clinical Trials Unit. Regain trial: rehabilitation exercise and psychological support after covid-19 infection. 2020. https://warwick.ac.uk/fac/sci/med/research/ctu/trials/regain/.

18 BMJ. Webinar: Post-covid conditions ("Long covid" and other sequelae of covid disease). YouTube. 15 Apr 2021. https://www.youtube.com/watch?v=2BeC_fVhAXs.

This article is made freely available for use in accordance with BMI's website terms and conditions for the duration of the covid-19 pandemic or until otherwise determined by BMJ. You may use, download and print the article for any lawful, non-commercial purpose (including text and data mining) provided that all copyright notices and trade marks are retained. 